\title{
Frame Element with Mixed Formulations for Composite and RC Members with Bond-Slip. II: Correlation Studies
}

\author{
Chin-Long Lee ${ }^{1}$ and Filip C. Filippou ${ }^{2}$
}

\begin{abstract}
This paper discusses the convergence and accuracy of the three mixed formulations in the companion paper for a new composite frame element that is suitable for the large-scale, largedisplacement inelastic analysis of structures. The convergence is assessed with the inelastic response of a steel-concrete composite substructure under uniaxial loading. The accuracy of the formulations is assessed by correlating the numerical results with experimental data from a steel-concrete composite substructure under uniaxial loading, and from the biaxial response of two reinforced concrete cantilever columns. The correlation studies confirm the accuracy and numerical robustness of the mixed formulations, for global response measures, such as the force-displacement relation, and for local response measures such as the strain and relative slip distributions in the composite member. Special emphasis in the numerical studies is placed on the challenging cyclic, biaxial response of the reinforced concrete cantilever columns that previous models are unable to capture. The paper concludes with an evaluation of the significance of the bond-slip interaction in reinforced concrete and composite elements on the local and global response of structural members.

Keywords: Steel-Concrete Composite Structures; Reinforced-Concrete Structures; Mixed Formulation; Bond-Slip; Convergence; Correlation; Three-Dimensional; Biaxial Cyclic Loading; Strain Distribution; Slip Distribution.
\end{abstract}

\footnotetext{
${ }^{1}$ Dept. of Civil \& Nat. Res. Eng., , Univ. of Canterbury, Private Bag 4800, Christchurch New Zealand 8140. E-mail: chin-long.lee@canterbury.ac.nz.

${ }^{2}$ Dept. of Civil \& Environ. Eng., Univ. of California, 760 Davis Hall, Berkeley, CA 94720-1710. E-mail: filippou@ce.berkeley.edu.
} 


\section{INTRODUCTION}

In the companion paper three formulations, a mixed-displacement (MD), a mixed-force $(\mathrm{MF})$, and a mixed-mixed (MM) formulation are proposed for describing the response of a composite member consisting of two or more components. The model, thus, applies to reinforced concrete (RC) beams and columns, steel-concrete composite beams, members with FRP reinforcement, and prestressed concrete and timber members with straight tendons. These mixed formulations are derived from the $\mathrm{Hu}$-Washizu variational principle after enhancing it with fields for the bond-slip interaction between the components of the composite member.

The proposed model is formulated so that the element degrees-of-freedom can be transformed to the structure reference system with a standard transformation. It is based on the co-rotational formulation (Felippa and Haugen, 2005, Le Corvec, 2012) so that it can be readily deployed for the large scale analysis of structures with composite members under nonlinear geometry effects due to large displacements.

This paper examines the convergence and accuracy of the three mixed formulations with the inelastic response of composite and reinforced concrete members. The inelastic response of a steel-concrete substructure under uniaxial monotonic loading is used for the study of the convergence characteristics of the formulations. The study discusses the effect of the number of interpolation segments for the bond-slip field variables on the global and local response of the substructure.

The accuracy of the formulations is assessed by correlating the numerical results with experimental data for the uniaxial response of a steel-concrete composite substructure by Bursi and Ballerini (1996), and the biaxial response of two reinforced concrete cantilever columns by Low and Moehle (1987) and Bousias et al. (1995). The global force-displacement relation and the local slip distributions and strain time histories are used in the accuracy evaluation of the proposed model.

The numerical simulations of steel-concrete composite specimens to date including the 
correlation of local stress, strain and slip distributions are typically limited to monotonic loading (e.g. Fragiacomo et al., 2004, Tort and Hajjar, 2010a;b, Lin and Zhang, 2013). Some numerical studies report the local stress, strain, and slip distributions of models under monotonic loading (e.g. Dall'Asta and Zona, 2002; 2004a;b, Sun and Bursi, 2005), or under cyclic loading (e.g. Zona et al., 2008) without correlation with experimental results.

In the numerical simulation of $\mathrm{RC}$ members with beam-column elements to date, the correlation of results with available experimental data is limited to the global response of the specimen under uniaxial loading (e.g. Monti and Spacone, 2000, Limkatanyu and Spacone, 2002, Ayoub, 2006, Fernandes et al., 2013). The study by Saatcioglu et al. (1992) reports the correlation of numerical results with experimental data, but only for the moment-rotation response without reference to local strain and relative slip distributions.

The general nature of the proposed mixed formulations in the companion paper permits a more detailed analysis of bond-slip phenomena in composite structural members under uniaxial or biaxial response than has been possible to date, as the following correlation studies aim to illustrate.

The following numerical simulations were performed with FEDEASLab (http://fedeaslab. berkeley.edu), a MatLab® toolbox for the simulation of the inelastic response of structures under static and transient load conditions (Filippou and Constantinides, 2004).

\section{CONVERGENCE STUDY}

The convergence characteristics of the three formulations are evaluated with the inelastic response of the steel-concrete composite substructure specimen with partial composite action by Bursi and Ballerini (1996). The geometry and configuration of the specimen are shown in Fig. 1(a). In the numerical model the composite beam and the steel column are represented with one frame element each, as shown in Fig. 1(b). The composite beam is modeled with the proposed composite element while a linear elastic element is used for the column. In the composite element the steel beam serves as Component 1 and the top slab as Component 2 . The shear studs connecting the steel beam with the top slab are modeled as a bond interface 
section. In the model the force-slip relationship of each stud is divided by the tributary area of the stud to give the bond stress-slip relation. The convergence study focuses on the relative slip between the steel beam and the concrete slab, while the relative slip between the reinforcing steel in the slab and the surrounding concrete is neglected. Since the concrete slab extends beyond the steel beam and wraps around the steel column, the relative slip between the slab and the steel beam at the beam-column interface is assumed to be zero throughout the loading history. The cross-section of the composite element is divided into fourteen layers: six layers for the reinforced concrete slab, two layers for each flange and four layers for the web of the steel beam.

The constitutive models used for concrete, steel and bond-slip of the shear studs are the Mander model (Mander et al., 1988) with no tensile resistance, the general Menegotto-Pinto (GMP) model (Menegotto and Pinto, 1973) modified by Filippou et al. (1983), and a model with a trilinear envelope, respectively. The trilinear model is similar to the Hysteretic model in OpenSees (Mckenna, 1997, http://opensees.berkeley.edu). Unless stated otherwise, these models are also used in all subsequent correlation studies.

For the concrete material model, the strength $f_{c}^{\prime}$ at 28 days is $36.8 \mathrm{MPa}$, the strain at maximum strength $\varepsilon_{c o}$ is 0.002 and the confinement ratio $K$ is 1 . For the steel material model, the Young modulus $E_{s}$ is $205 \mathrm{GPa}$, the yield strength $f_{y}$ is $329 \mathrm{MPa}$ and the strain hardening ratio $b$ is $1.4 \%$. For the bond-slip model, the transition points of the trilinear monotonic envelope are given by the following slip-stress value pairs $(0.2 \mathrm{~mm}, 1.0 \mathrm{MPa})$, $(2 \mathrm{~mm}, 1.9 \mathrm{MPa})$ and $(8 \mathrm{~mm}, 2.04 \mathrm{MPa})$. The bond stress at a slip value larger than 8 $\mathrm{mm}$ follows the slope of the last linear branch until reaching a zero stress. This trilinear envelope approximates the monotonic force-deformation relation of shear studs from a series of experiments by Ollgaard et al. (1971).

Whereas the convergence rate of a finite element is well defined for elastic response, it is not well defined for inelastic response and will not be reported in quantitative terms here. Instead, the following results show qualitatively the convergence characteristics of 
the proposed mixed formulations for the inelastic response of composite structures with increasing number of interpolation segments for the bond stress-slip fields in the composite element. Details of the convergence rate of the composite element for elastic response can be found in the Ph.D. thesis by Lee (2008).

To evaluate the convergence characteristics of the composite beam element, the bondslip fields are represented with 1, 2, 4, 8, 16, 32 and 64 interpolation segments of equal length inside the element. The inelastic response of the beam with the MD solution with 64 interpolation segments in Fig. 2 is used as the reference response for the determination of the relative errors of the three mixed formulations.

For the convergence study the specimen is subjected to a displacement-controlled monotonic load at the left end up to a horizontal translation value of $80 \mathrm{~mm}$, as shown by the force-displacement $(P-U)$ relation at the point of load application in Fig. 2. The discussion of the convergence characteristics of the three mixed formulations focuses on the resisting force $P$ of the specimen, and on the axial force distribution of the concrete slab, $N_{c}(x)$, and the relative slip distribution at the interface between the concrete slab and the steel beam $u_{b}(x)$ with $x$ measuring the distance from the left specimen end. Fig. 2 shows the reference solution for these distributions at horizontal translation values $U$ of $20 \mathrm{~mm}$ and $80 \mathrm{~mm}$. The slip values are positive when the concrete slab slips towards the right relative to the steel beam.

Fig. 3 compares the convergence characteristics of the three mixed formulations with increasing number of interpolation segments at a horizontal translation $U$ of $20 \mathrm{~mm}$ on the left and at translation $U$ of $80 \mathrm{~mm}$ on the right. The first row of the figure refers to the relative errors of the resisting force $P$ at the point of load application, the second row refers to the relative error of the axial force $N_{c}$ at the right end of the concrete slab, and the third row to the relative error of the relative slip $u_{b}$ at the interface between the concrete slab and the steel beam at the left end of the specimen.

The relative error results in Fig. 3 lead to the following conclusions: 
1. The MD and MM formulations have similar convergence characteristics with the relative error consistently decreasing with increasing number of segments.

2. In the MF formulation, the relative error fails to consistently decrease with increasing number of segments, but this only happens for relative errors that are much smaller than $1 \%$.

3. The MF formulation is the most accurate of the three in terms of the global response variable $P$, and the local response variables $N_{c}$ and $u_{b}$. It is surprising that the MF formulation gives a more accurate relative slip value at the left end of the specimen, despite the fact that it lacks a relative slip field interpolation.

4. Two interpolation segments suffice for a relative error in the resisting force $P$ that is smaller than $1 \%$, but four or more interpolation segments are necessary for a similar value of relative error for the axial force $N_{c}$ and the relative slip $u_{b}$.

5. Fewer interpolation segments are required with the MF formulation than with the MD or MM formulation for the same relative error in the global and local response values.

\section{CORRELATION STUDIES WITH EXPERIMENTAL RESULTS}

The accuracy of the formulations is assessed by correlating the numerical results with experimental data for a steel-concrete composite substructure under uniaxial loading by Bursi and Ballerini (1996), and for the biaxial response of two reinforced concrete cantilever columns by Low and Moehle (1987) and Bousias et al. (1995).

The experimental studies to establish the bond-slip relation between reinforcing steel and concrete as well as between the components of composite structural members continue to this date suggesting that the objective to establish a general bond-slip relation under all loading scenarios and for all materials and failure mechanisms has not been reached, Eligehausen et al. (1983), Alsiwat and Saatcioglu (1992), Luccioni et al. (2005), Bamonte and Gambarova (2007), Harajli (2009), Wu and Zhao (2013), among others. Moreover, there is considerable scatter in the experimental measurements stemming from the sensitivity to imperfections 
and local features of the devices used to enhance the bond-slip behavior of components. Consequently, the parameters of the bond-slip model in the following correlation studies have been adjusted on a case-by-case basis to give a reasonable match with experimental results. These adjustments are described for each case and remain within the scatter of available experimental data.

\section{Steel-Concrete Composite Substructure by Bursi-Ballerini}

The specimen geometry and material properties for the composite substructure by BursiBallerini were described in connection with the convergence study and are shown schematically in Fig. 1. The numerical model for the correlation study is similar to the one for the convergence study, but uses one interpolation segment for the left half of the specimen and two equal length interpolation segments for the right half in order to represent better the more pronounced variation of the relative slip and the beam curvature in the region.

The parameters of the constitutive models for the concrete and the steel are those used in the convergence study. The trilinear bond-slip envelope at the interface between the concrete slab and the steel beam is described by the slip-stress value pairs of $(0.2 \mathrm{~mm}, 1.4 \mathrm{MPa}),(0.6$ $\mathrm{mm}, 1.9 \mathrm{MPa})$, and (2 mm, 2.7 MPa). The positive bond-slip envelope corresponding to the concrete slab slipping to the right relative to the steel beam is scaled down by $20 \%$ relative to the negative envelope, so as to represent the reduced strength of the shear studs upon slip reversal following the first significant inelastic slip of the deck. A consistent damage model for this relation will be explored in a future study.

The bond-slip relation deviates by about 30\% in terms of strength from the proposal by Ollgaard et al. (1971) so as to match the local measurements from the composite specimen by Bursi and Ballerini (1996). The bond-slip model uses two pinching parameters $\rho_{x}=0.5$ and $\rho_{y}=0.25$ for a better representation of the experimental hysteretic behavior of the connectors. These parameters are described in the documentation for the hysteretic model of OpenSees (http://opensees. berkeley.edu).

The steel-concrete substructure specimen by Bursi-Ballerini was pulled and pushed at 
the left end under horizontal displacement control with amplitudes ranging from $3 \mathrm{~mm}$ to $110 \mathrm{~mm}$. At a horizontal displacement amplitude of $35 \mathrm{~mm}$ and $75 \mathrm{~mm}$ the specimen was subjected to three cycles. Local buckling of the steel beam initiated in the experiment at a horizontal displacement of $75 \mathrm{~mm}$, leading to beam failure at a displacement amplitude of $110 \mathrm{~mm}$. Because the proposed model does not account for local buckling, the correlation study is limited to cycles up to a horizontal displacement amplitude of $75 \mathrm{~mm}$.

Fig. 4 compares the numerical with the experimental results for the MD, MM and MF formulations. The force versus horizontal translation relation at the point of load application is shown on the left of Fig. 4. The relation between the applied force and the relative slip between the concrete slab and the steel beam at approximately the first quarter span point (Sec. 1), and at the third quarter span point (Sec. 3) from the left specimen end is shown on the right of Fig. 4. In these plots a positive displacement corresponds to the specimen being pulled to the left, and a negative displacement to the specimen being pushed. Because the monitoring points for the bond-slip relation in the model are not exactly located at Sec. 1 and Sec. 3, the slip values at these locations are determined by linear interpolation of the values at the nearest integration points.

Fig. 4 shows that all mixed formulations give reasonably accurate global and local response values for the composite beam. The stiffening effect due to the closing of concrete cracks when the concrete slab is subjected to compression is represented well in the model. Fig. 4 shows, however, that the accuracy of the local response is inferior to that for the global response. At Sec. 1, the negative slip (PUSH) is represented well by the three mixed formulations, but the positive slip (PULL) is underestimated. The opposite is true at Sec. 3, where the positive slip (PULL) is represented well by the three mixed formulations, but the negative slip (PUSH) is underestimated.

Fig. 5 compares the slip distribution of the model with the measurements from the specimen at the peak horizontal translation for the last four loading cycles before buckling initiation of the steel beam. The slip distribution correlation with the experimental results is 
very good for all three mixed formulations. The numerical results slightly underestimate the measured slip at the the slab-beam interface region with $x \leq 0.7 L$, but slightly overestimate the relative slip near the column under pull conditions, and slightly underestimate the relative slip near the column under push conditions. Numeric parametric studies show that the discrepancy is not reduced with increasing number of interpolation segments for the bond-slip representation. The complex force transfer mechanism near the column and the associated shear lag effect in the concrete slab may be responsible for this discrepancy, an effect that the proposed model does not account for.

At the peak of the first cycle at a horizontal translation of $75 \mathrm{~mm}$ to the right (PUSH), the slip value near the column for the MD formulation in the lower figure of Fig. 5 appears to be closer to the experimental measurements than those for the MM and MF formulations. With increasing number of interpolation segments for the slip field, however, the slip values of the MD formulation approach those for the MM and MF formulations at the slab-beam interface region with $x>0.7 L$. This confirms the earlier conclusion that the MD formulation requires more interpolation segments for the same level of accuracy in local response as the MM and MF formulations.

In conclusion, the correlation study of the numerical results with the measurements of the steel-concrete composite specimen shows that the MD, MM and MF formulations represent the global and the local response of the specimen with good accuracy. The slight discrepancy in the relative slip values near the beam-column connection is attributed to the complex stress transfer associated with shear lag that the model does not account for.

\section{Reinforced-Concrete Cantilever Column by Bousias}

The next correlation study involves the square reinforced concrete cantilever column specimen by Bousias et al. (1995). Fig. 6(a) shows the geometry and the reinforcing details of the specimen, as well as the model discretization in one composite frame element and 8 anchored bar elements, one for each reinforcing bar.

The cantilever column was subjected to a constant axial compression of approximately 
$200 \mathrm{kN}$ and a biaxial horizontal tip displacement history with the nested 'butterfly-shaped' pattern of proportionally increasing amplitude after each cycle in Fig. 6(b). The numbers in Fig. 6(b) denote the sequence of imposed tip displacements. The model of the cantilever column accounts for the nonlinear chord rotation effect, the so-called P- $\Delta$ effect.

Because of the earlier conclusions from the convergence and the first correlation study about the superiority of the MF formulation relative to the MD and MM formulations, and the conclusion from the fixed-end rotation study in the companion paper about the ability of the MF formulation to represent the discontinuity in the relative slip field at the columnfoundation interface, the cantilever column model in Fig. 6(a) uses the MF formulation for the RC column element with slip in the reinforcement, and the 8 anchored bar elements, one for each reinforcing bar. The column element has only one interpolation segment for the bond-slip field, while the anchored reinforcing bar elements use two interpolation segments. The length ratio of the anchored bar segments is 1 to 2 , with the shorter segment starting at the column base. The column cross section is discretized with a grid of 10x10 fibers, with a grid of $6 \mathrm{x} 6$ fibers for the confined concrete core and the remainder for the unconfined cover.

The slip of the reinforcing bars is assumed to be zero at the cantilever tip, while the slip of the reinforcing bars at the end of the anchored length is restrained with an extensional spring, one for each slip DOF. These springs represent the bond-slip behavior of the hook anchorage following the recommendations of the experimental study by Eligehausen et al. (1982) with a significant higher peak bond stress value for the same relative slip.

The parameters for the Mander concrete model are $f_{c}^{\prime}=25.7 \mathrm{MPa}, \varepsilon_{c o}=0.003$ and $K=1.25$ for the confined core with $K=1.00$ for the unconfined cover. The steel model parameters are $E_{s}=205 \mathrm{GPa}, f_{y}=460 \mathrm{MPa}$ and $b=1.13 \%$. For the bond-slip relation of the reinforcing bars two sets of parameters are used: one for the reinforcing bar segment bonded to the column core concrete and another for the segment bonded the foundation concrete, which lacks transverse reinforcement.

The bond-slip relation uses a piecewise linear envelope with 4 segments defined by 4 
bond stress-slip pairs with the last segment added to the bond-slip relation of the preceding study so as to capture the softening response under a large relative slip value characterizing anchorage failure. The four stress-slip pairs for the bond stress-slip relation of the bar segment surrounded by the confined concrete of the column are $(0.25 \mathrm{~mm}, 7.88 \mathrm{MPa}),(1$ mm, 13.5 MPa), (3 mm, 13.6 MPa), and (10.5 mm, $6 \mathrm{MPa})$. The four stress-slip pairs for the bond stress-slip relation of the bar segment surrounded by the concrete of the foundation are $(0.125 \mathrm{~mm}, 1.31 \mathrm{MPa}),(0.5 \mathrm{~mm}, 2.25 \mathrm{MPa}),(3 \mathrm{~mm}, 2.27 \mathrm{MPa})$, and $(10.5 \mathrm{~mm}, 0.75$ $\mathrm{MPa}$. These parameters are based on the recommendations from the experimental study by Eligehausen et al. (1983) and are similar to the parameters of the study by Ayoub (2006), except that the peak bond stress of the anchored bars and the residual bond strength for slip values greater than $10.5 \mathrm{~mm}$ are reduced by $50 \%$ to account for the fact that the foundation concrete is unconfined (Gutierrez et al., 1993). The multi-linear bond-slip relation does not include pinching and damage.

The force-displacement relation of the spring at the end of each anchored bar is based on a trilinear envelope with the following stress-slip value pairs: $(0.125 \mathrm{~mm}, 4.69 \mathrm{kN}),(0.5 \mathrm{~mm}$, $8.04 \mathrm{kN})$, and $(3 \mathrm{~mm}, 8.12 \mathrm{kN})$. The yield force of $8.04 \mathrm{kN}$ corresponds to a bearing stress of $400 \mathrm{MPa}$ following the recommendation of the experimental study by Eligehausen et al. (1982). The trilinear bond-slip model uses two pinching parameters $\rho_{x}=0.5$ and $\rho_{y}=0.1$ to represent the hysteretic behavior of the anchorage hook. These parameters are described in the documentation for the hysteretic model of OpenSees (http://opensees . berkeley . edu).

Fig. 7 compares the numerical results for the force-tip displacement response of the column with experimental measurements. The first row of the figure shows the force-tip displacement relation in the $X$-direction on the left, and in the $Y$-direction on the right with reference to the displacement history in Fig. 6(b). The agreement of the model that includes the bond-slip of the reinforcing bars with the experimental results is excellent.

To assess the influence of the relative slip of the reinforcement on the cantilever column response, the second row of Fig. 7 shows the force-tip displacement relation for a numerical 
model with perfect bond of the reinforcing steel. It is clear from these figures that the effect of the relative slip of the reinforcement on the column strength and stiffness is appreciable.

This is further corroborated by the comparison of the axial displacement history of the model with partial or perfect bond with the experimental data in the last row of Fig. 7 . The ratcheting effect of the column results from the accumulation of residual tensile strains in the reinforcing bar anchorage and the associated reinforcing bar pull-out (Bousias et al., 1995). The last row of Fig. 7 shows that this phenomenon is represented very well by the model with bond-slip of the reinforcing bars in the column and in the foundation, but is underestimated by the model with perfect bond.

Fig. 8 shows the pull-out slip history of the eight reinforcing bars at the column base. The results in Fig. 8 show the gradual pull-out of the reinforcing bars at the left and at the right edge of the cross-section. The largest pull-out of approximately $8 \mathrm{~mm}$ is observed in the bottom left corner and in the upper right corner reinforcing bars and is consistent with the largest measured axial displacement value of $4 \mathrm{~mm}$ at the center of the column top in Fig. 7, after accounting for the push-in of the reinforcing bar at the opposite end of the base section and the elongation of the column.

\section{Reinforced-Concrete Cantilever Column by Low-Moehle}

The next correlation study involves the rectangular reinforced concrete cantilever column specimen by Low and Moehle (1987). Fig. 9 shows the geometry and the reinforcing details of the specimen, as well as the model discretization in one composite frame element and 10 anchored bar elements, one for each reinforcing bar.

The model for this RC cantilever column is similar to that used in the preceding correlation study. The differences regard the specimen geometry, the shape of the cross section, the material parameters, the interesting 'cloverleaf' pattern for the biaxial lateral displacement history in Fig. 9 with a variable axial force that accounts for the overturning effect in building columns, the reinforcement details, and the fact that for the experiments by Low and Moehle (1987) the pull-out of the reinforcing bars from the foundation was measured. 
The parameters for the Mander concrete model are $f_{c}^{\prime}=4.6 \mathrm{ksi}(31.7 \mathrm{MPa}), \varepsilon_{c o}=0.003$ and $K=1.35$ for the confined core with $K=1.00$ for the unconfined cover; the steel model parameters are $E_{s}=29000 \mathrm{ksi}(200 \mathrm{GPa}), f_{y}=65 \mathrm{ksi}(448 \mathrm{MPa})$ and $b=1.8 \%$ for the \#3 re-bars, and $f_{y}=73 \mathrm{ksi}(503 \mathrm{MPa})$ and $b=1 \%$ for $\# 2$ re-bars.

In contrast to the column specimen by Bousias et al. (1995), the concrete in the foundation of the column specimen by Low and Moehle (1987) is well confined, so that a single set of parameters for the bond stress-slip relation was used for the reinforcing bar segments in the column and in the foundation.

Near the column-foundation interface a pull-out cone forms in the foundation that adversely affects the bond-slip behavior of the reinforcing bar under a pulling force, but does not affect the bond-slip behavior under a compression force that pushes the reinforcing bar into the foundation according to experimental observations by Eligehausen et al. (1983). To account for this effect in the model, the values of the bond-stress slip envelope under pull-out conditions are reduced by $60 \%$ with respect to the values under push-in conditions.

The imposed biaxial displacement history at the top of the column involves five cycles with peak displacement values $U_{X}$ and $U_{Y}$ in the global $X$ and $Y$ direction, respectively, of 0.16 in., 0.32 in., 0.16 in., 0.64 in., and 0.96 in. $(4.06 \mathrm{~mm}, 8.13 \mathrm{~mm}, 4.06 \mathrm{~mm}, 16.3 \mathrm{~mm}$, and $24.4 \mathrm{~mm})$. The magnitude of the applied axial load ranges from 0.5 kips $(2.22 \mathrm{kN})$ to 20 kips $(89 \mathrm{kN})$ of compression with a value of $10 \mathrm{kips}(44.5 \mathrm{kN})$ at $U_{X}=0$, and varies almost linearly with the displacement in the $X$-direction, as shown in Fig. 9. The model of the cantilever column accounts for the nonlinear chord rotation effect, the so-called P- $\Delta$ effect.

Fig. 10 correlates the numerical results with the experimental measurements: the topmost plot and the one below it show that the model is subjected exactly to the measured horizontal displacement time history in the $X$ - and $Y$-direction, respectively; the two plots in the middle compare the resisting force time histories of the model with those measured for the specimen in the $X$-and $Y$-direction; finally, the two plots at the bottom of the figure compare the numerical strain history of the top left and bottom right reinforcing bar with experimental 
strain gauge measurements at a distance of 0.5 in. $(12.7 \mathrm{~mm})$ from the column base. It is evident from the strain history of the top left reinforcing bar that the strain gauge went out of range near load step 420 .

To assess the influence of the relative slip of the reinforcement on the specimen strength, and on the reinforcing strain values the plots of Fig. 10 include the numerical results for a model with perfect bond of the reinforcing steel in the column and in the foundation.

The correlations in Fig. 10 lead to the conclusion that the numerical results for the resisting force of the model with partial or perfect bond agree well with the experimental measurements, but the column strength history for the model with partial bond is decidedly better than for the model with perfect bond. The latter overestimates the strength by a percentage similar to the preceding correlation study.

The effect of the relative slip of the reinforcing bars is very prominent in the strain histories of the top left and bottom right reinforcing bar in Fig. 10. The correlation of the numerical results with the experimental measurements shows excellent agreement for the model with partial bond, particularly, when accounting for the sensitivity of the measured data to the location of the strain gauge relative to the crack locations and the sensitivity of the numerical data to the assumed value for the concrete tensile strength and for the strain hardening ratio of the reinforcing steel. By contrast, the maximum reinforcing bar strains of the model with perfect bond are as much as four to six times larger than the measured values at the largest lateral displacement of the column.

The proposed model is, therefore, capable of representing this important local response parameter with very good accuracy and should be a valuable tool for the assessment of the local behavior of reinforced concrete columns under cyclic loading conditions before the onset of reinforcement buckling.

\section{CONCLUSIONS}

This paper discusses the convergence and accuracy of the three mixed formulations in the companion paper for a new composite frame element suitable for simulating the hys- 
teretic behavior of reinforced concrete (RC) beams and columns with reinforcing bar slip, steel-concrete composite beams with partial bond, members with FRP reinforcement, and prestressed concrete and timber members with straight tendons.

The paper first studies the convergence characteristics of the three mixed formulations and then assesses their relative accuracy with correlation studies of the numerical results with experimental measurements of the inelastic response of a steel-concrete composite substructure under uniaxial loading, and of the inelastic biaxial response of two reinforced concrete cantilever columns (Bursi and Ballerini, 1996, Low and Moehle, 1987, Bousias et al., 1995).

The correlation studies confirm the accuracy and numerical robustness of the mixed formulations with reference to the cyclic force-displacement relation and the local strain and relative slip distributions of the constituent components.

The convergence study shows that

- the MF formulation gives the most accurate global and local response estimates for a composite element, whereas

- the performance of the MD and MM formulations are similar but inferior to the MF formulation.

- Fewer interpolation segments for the relative slip fields are required with the MF formulation than with the MD or MM formulation for the same relative error in global and local response estimates.

The correlation studies show that

- All three formulations are capable of representing accurately the load-displacement response and the relative slip distribution of structural members with partial bond.

- The need for fewer interpolation segments for the relative slip fields with the MF formulation make it the most economical of the three approaches for the same level of accuracy.

- The proposed model is capable of describing the reduced strength and stiffness of 
structural members under partial bond.

- The proposed model is capable of describing several global and local response variables of the cyclic inelastic biaxial response of reinforced concrete columns, such as the ratcheting effect in the axial displacement history, and the reinforcing bar strain histories at the column-foundation interface.

- The inclusion of the relative slip of the reinforcing bars is very significant for the accurate determination of the maximum steel strain values, and the prediction of bar fracture. An accurate assessment of this local response parameter is impossible with a model with perfect bond between components.

The proposed model is formulated so that it can be readily deployed in a general purpose finite element program and accounts for the nonlinear geometry effects under large displacements with the corotational formulation. It holds significant promise for the better assessment of the inelastic response of structural members with partial bond between constituent components.

\section{REFERENCES}

Alsiwat, J. M. and Saatcioglu, M. (1992). "Reinforcement anchorage slip under monotonic loading." Journal of Structural Engineering, 118(9), 2421-2438.

Ayoub, A. S. (2006). "Nonlinear analysis of reinforced concrete beam-columns with bondslip." Journal of Engineering Mechanics, 132(11), 1177-1186.

Bamonte, P. and Gambarova, P. (2007). "High-bond bars in NSC and HPC: study on size effect and on the local bond stress-slip law." Journal of Structural Engineering, 133(2), $225-234$.

Bousias, S. N., Verzeletti, G., Fardis, M. N., and Gutierrez, E. (1995). "Load-path effects in column biaxial bending with axial force." Journal of Engineering Mechanics, 121(5), 596-605. 
Bursi, O. S. and Ballerini, M. (1996). "Behaviour of a steel-concrete composite substructure with full and partial shear connection." The Eleventh World Conference on Earthquake Engineering, Acapulco. Paper No. 771.

Dall'Asta, A. and Zona, A. (2002). "Non-linear analysis of composite beams by a displacement approach." Computers $\& 5$ Structures, 80(27-30), 2217-2228.

Dall'Asta, A. and Zona, A. (2004a). "Comparison and validation of displacement and mixed elements for the non-linear analysis of continuous composite beams." Computers $\&$ Structures, 82(23-26), 2117-2130.

Dall'Asta, A. and Zona, A. (2004b). "Three-field mixed formulation for the non-linear analysis of composite beams with deformable shear connection." Finite Elements in Analysis and Design, 40(4), 425-448.

Eligehausen, R., Bertero, V. V., and Popov, E. E. (1982). "Hysteretic behavior of reinforcing deformed bars in r/c joints." The seventh European conference on earthquake engineering, Vol. 4, Athens, Greece, 171-178.

Eligehausen, R., Popov, E. P., and Bertero, V. V. (1983). "Local bond stress-slip relationships of deformed bars under generalized excitations : experimental results and analytical model." Report No. EERC 83/23, Earthquake Engineering Research Center, University of California, Berkeley.

Felippa, C. and Haugen, B. (2005). "A unified formulation of small-strain corotational finite elements: I. theory." Computer Methods in Applied Mechanics and Engineering, 194(21), $2285-2335$.

Fernandes, C., Varum, H., and Costa, A. (2013). "Importance of the bond-slip mechanism in the numerical simulation of the cyclic response of $\mathrm{RC}$ elements with plain reinforcing bars." Engineering Structures, 56, 396-406. 
Filippou, F. C. and Constantinides, M. (2004). "FEDEASLab getting started guide and simulation examples." Report No. NEESgrid-2004-22, Dept. of Civil and Environmental Eng., University of California at Berkeley.

Filippou, F. C., Popov, E. P., and Bertero, V. V. (1983). "Effects of bond deterioration on hysteretic behavior of reinforced concrete joints." Report No. UCB/EERC-83/19, Earthquake Engineering Research Center, University of California, Berkeley.

Fragiacomo, M., Amadio, C., and Macorini, L. (2004). "Finite-element model for collapse and long-term analysis of steel-concrete composite beams." Journal of Structural Engineering, 130(3), 489-497.

Gutierrez, E., Magonette, G., and Verzeletti, G. (1993). "Experimental studies of loading rate effects on reinforced-concrete columns." Journal of Engineering Mechanics, 119(5), $887-904$.

Harajli, M. (2009). "Bond stress-slip model for steel bars in unconfined or steel, FRC, or FRP confined concrete under cyclic loading." Journal of structural engineering, 135(5), $509-518$.

Le Corvec, V. (2012). "Nonlinear 3d frame element with multi-axial coupling under consideration of local effects." Ph.D. thesis, University of California, Berkeley.

Lee, C.-L. (2008). "Hu-Washizu 3d frame formulations including bond-slip and singular section response." Ph.D. thesis, University of California, Berkeley.

Limkatanyu, S. and Spacone, E. (2002). "Reinforced concrete frame element with bond interfaces. II: State determinations and numerical validation." Journal of Structural Engineering, 128(3), 356-364.

Lin, X. and Zhang, Y. (2013). "Novel composite beam element with bond-slip for nonlinear 
finite-element analyses of steel/FRP-reinforced concrete beams." Journal of Structural Engineering, 139(12) 06013003.

Low, S. S. and Moehle, J. P. (1987). "Experimental study of reinforced concrete columns subjected to multi-axial cyclic loading." Report No. EERC 8\%-14, Earthquake Engineering Research Center, University of California, Berkeley.

Luccioni, B. M., López, D. E., and Danesi, R. F. (2005). "Bond-slip in reinforced concrete elements." Journal of Structural Engineering, 131(11), 1690-1698.

Mander, J. B., Priestley, M. J. N., and Park, R. (1988). "Theoretical stress-strain model for confined concrete." Journal of Structural Engineering, 114(8), 1804-1826.

Mckenna, F. T. (1997). "Object-oriented finite element programming: frameworks for analysis, algorithms and parallel computing." Ph.D. thesis, University of California, Berkeley.

Menegotto, M. and Pinto, P. E. (1973). "Method of analysis for cyclically loaded reinforced concrete plane frames including changes in geometry and non-elastic behavior of elements under combined normal force and bending." IABSE Symposium on Resistance and Ultimate Deformability of Structures Acted on by Well Defined Repeated Loads, Lisbon, 15-22.

Monti, G. and Spacone, E. (2000). "Reinforced concrete fiber beam element with bond-slip." Journal of Structural Engineering, 126(6), 654-661.

Ollgaard, J. G., Slutter, R. G., and Fisher, J. W. (1971). "Shear strength of stud connectors in lightweight and normal-weight concrete." Engineering Journal-American Institute of Steel Construction Inc, 8(2), 55-64.

Saatcioglu, M., Alsiwat, J. M., and Ozcebe, G. (1992). "Hysteretic behavior of anchorage slip in R/C members." Journal of Structural Engineering, 118(9), 2439-2458.

Sun, F.-F. and Bursi, O. S. (2005). "Displacement-based and two-field mixed variational 
formulations for composite beams with shear lag." Journal of Engineering Mechanics, 131(2), 199-210.

Tort, C. and Hajjar, J. F. (2010a). "Mixed finite element for three-dimensional nonlinear dynamic analysis of rectangular concrete-filled steel tube beam-columns." Journal of Engineering Mechanics, 136(11), 1329-1339.

Tort, C. and Hajjar, J. F. (2010b). "Mixed finite-element modeling of rectangular concretefilled steel tube members and frames under static and dynamic loads." Journal of Structural Engineering, 136(6), 654-664.

Wu, Y.-F. and Zhao, X.-M. (2013). "Unified bond stress-slip model for reinforced concrete." Journal of Structural Engineering, 139(11), 1951-1962.

Zona, A., Barbato, M., and Conte, J. P. (2008). "Nonlinear seismic response analysis of steel-concrete composite frames." Journal of Structural Engineering, 134(6), 986-997. 
NOTATION

The following symbols are used in this paper:

$b=$ strain hardening ratio;

$E_{s}=$ steel Young's modulus;

$f_{c}^{\prime}=$ concrete strength at 28 days;

$f_{y}=$ steel yield strength;

$K=$ confinement ratio of concrete strength;

$L=$ element length;

$N_{c}=$ concrete axial force;

$P=$ structural force;

$U=$ structural displacement;

$u_{b}=$ relative slip;

$x=$ position in element; and

$\varepsilon_{c o}=$ the strain at maximum strength. 


\section{List of Figures}

1 Composite substructure by Bursi and Ballerini (1996) and numerical model for convergence study . . . . . . . . . . . . . . . . . .

2 Load-displacement relation $P-U$, concrete axial force distribution $N_{c}(x)$ and relative slip distribution $u_{b}(x)$ for the MD formulation with 64 segments . . .

3 Relative errors for the force $P$, the axial force $N_{c}$, and the relative slip $u_{b}$ for the three mixed formulations in terms of the number of interpolation segments at a horizontal translation $U$ of $20 \mathrm{~mm}$ and $80 \mathrm{~mm} \ldots \ldots . . . . . .25$

4 Correlation of experimental measurements for the composite substructure by Bursi and Ballerini (1996) with numerical results for the MD, MM and MF

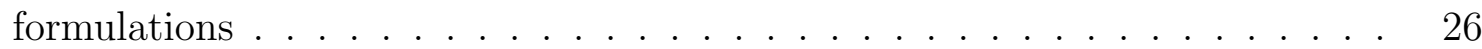

5 Comparison of the slip distribution at a peak displacement of $35 \mathrm{~mm}$ for three loading cycles and at a peak displacement of $75 \mathrm{~mm}$ for one cycle . . . . . . 27

6 Specimen geometry, numerical model, and displacement load history for square RC column specimen by Bousias et al. (1995) . . . . . . . . . . . . . 28

7 Force-displacement relation and axial displacement history for the RC cantilever column specimen by Bousias et al. (1995) . . . . . . . . . . . . . . . . 29

8 Reinforcing bar slip history at the base of the RC cantilever column by Bousias et al. (1995) . . . . . . . . . . . . . . . . . . . 30

$9 \quad$ Specimen geometry, numerical model, and force and displacement load history for rectangular RC column specimen by Low and Moehle (1987) . . . . . . . 31

10 Comparison of numerical results for the $\mathrm{RC}$ cantilever column strength history and the reinforcing bar strain histories with experimental measurements by Low and Moehle (1987) . . . . . . . . . . . . . . . . . . 32 


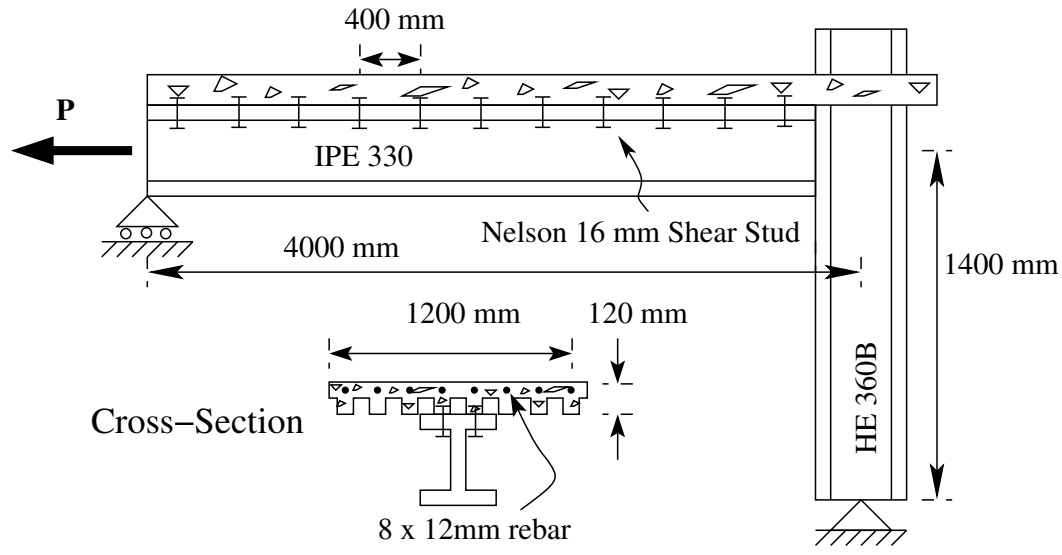

(a) Bursi-Ballerini composite substructure

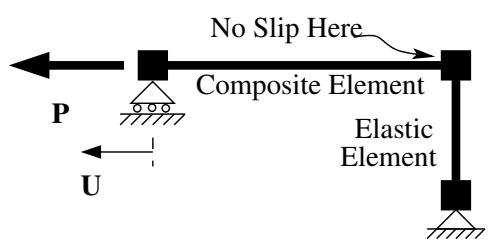

(b) Numerical model

FIG. 1. Composite substructure by Bursi and Ballerini (1996) and numerical model for convergence study 


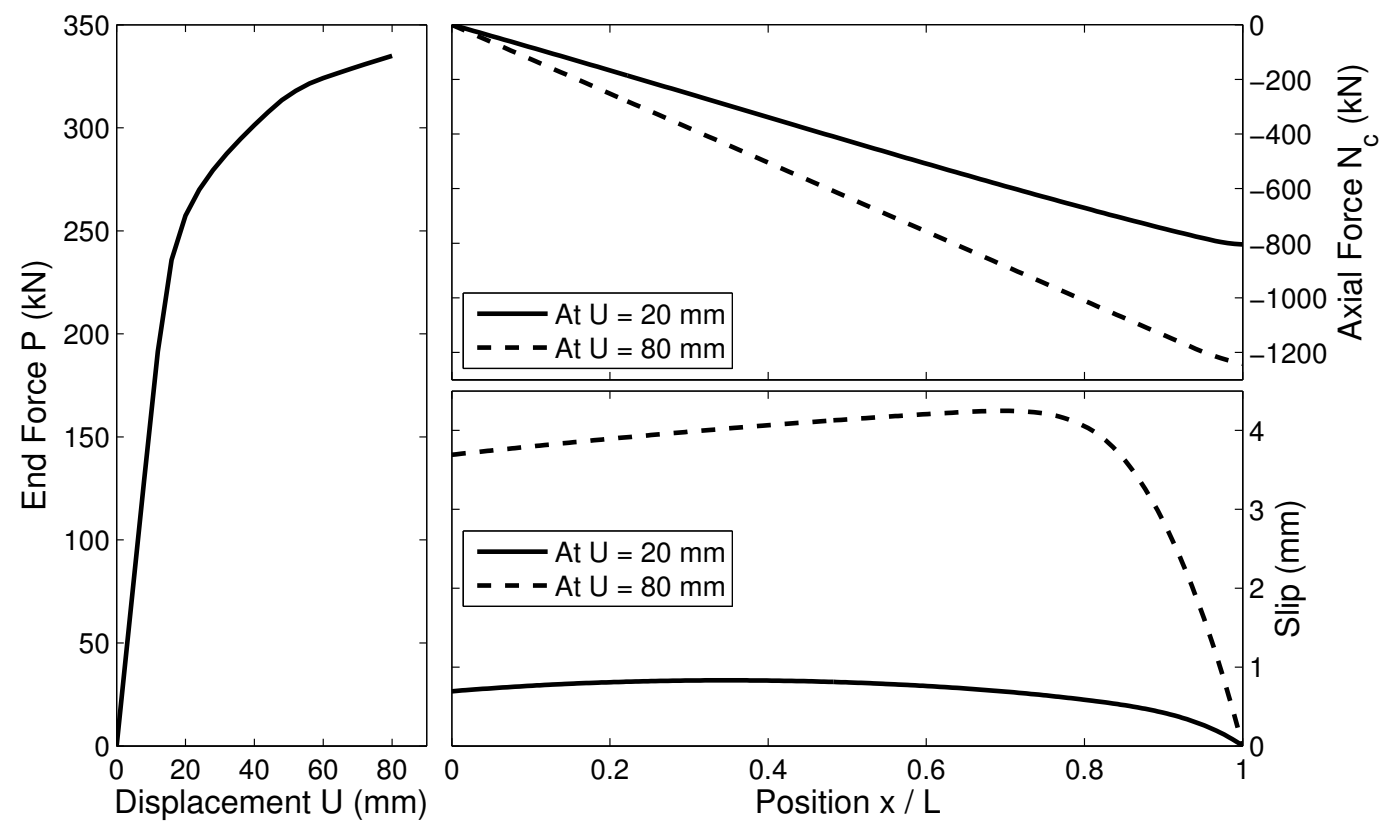

FIG. 2. Load-displacement relation $P-U$, concrete axial force distribution $N_{c}(x)$ and relative slip distribution $u_{b}(x)$ for the MD formulation with 64 segments 


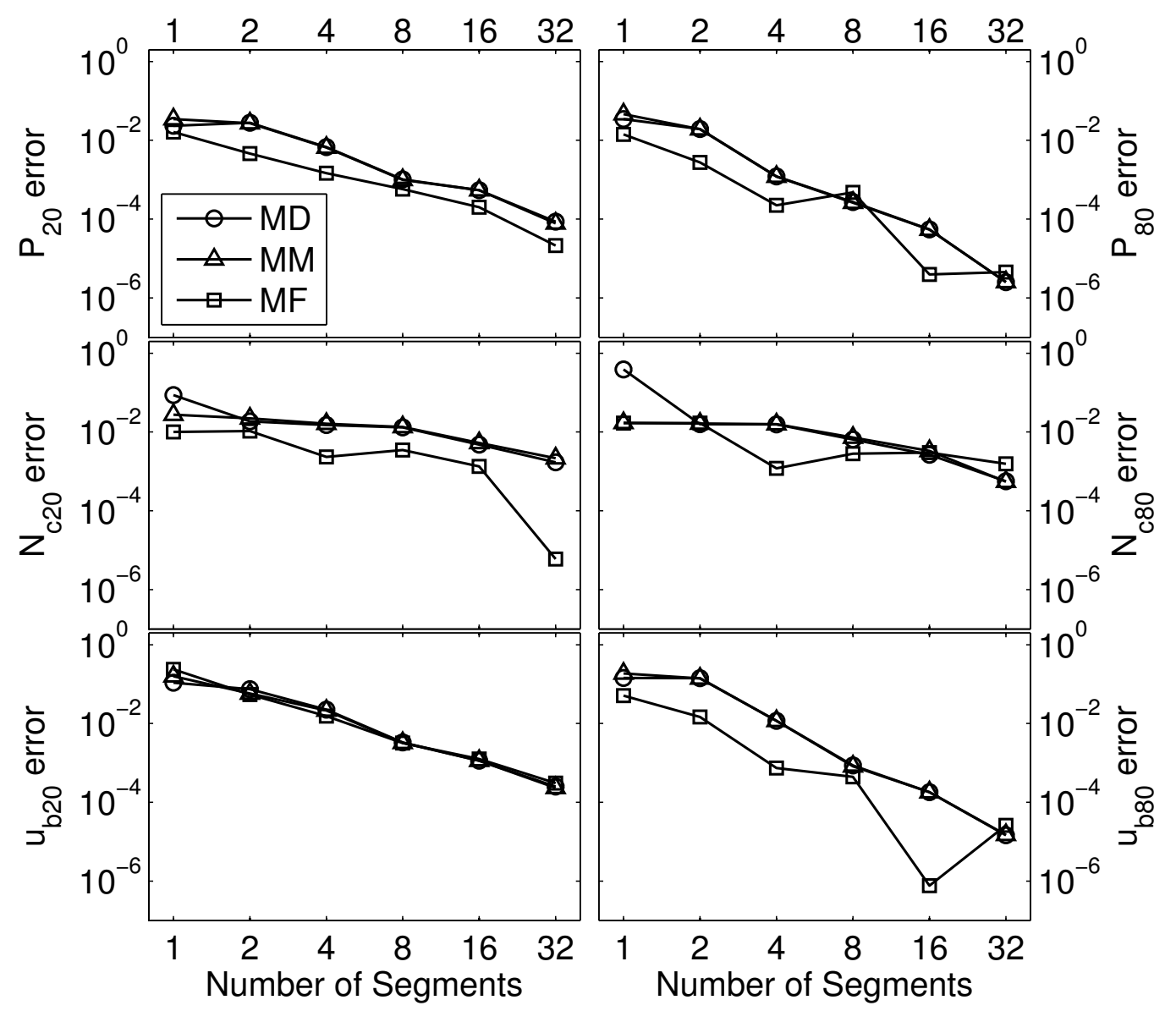

FIG. 3. Relative errors for the force $P$, the axial force $N_{c}$, and the relative slip $u_{b}$ for the three mixed formulations in terms of the number of interpolation segments at a horizontal translation $U$ of $20 \mathrm{~mm}$ and $80 \mathrm{~mm}$ 

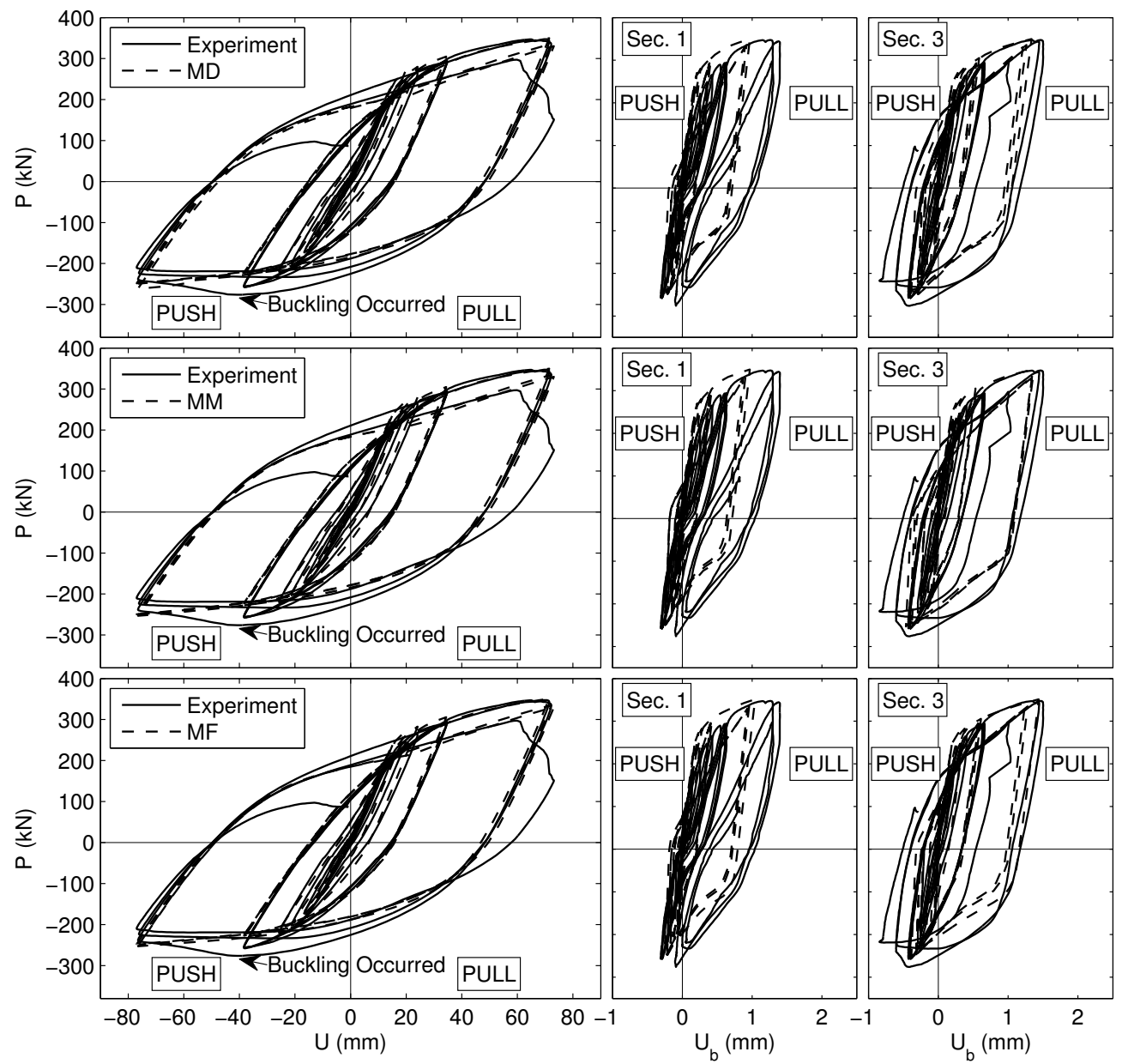

FIG. 4. Correlation of experimental measurements for the composite substructure by Bursi and Ballerini (1996) with numerical results for the MD, MM and MF formulations 


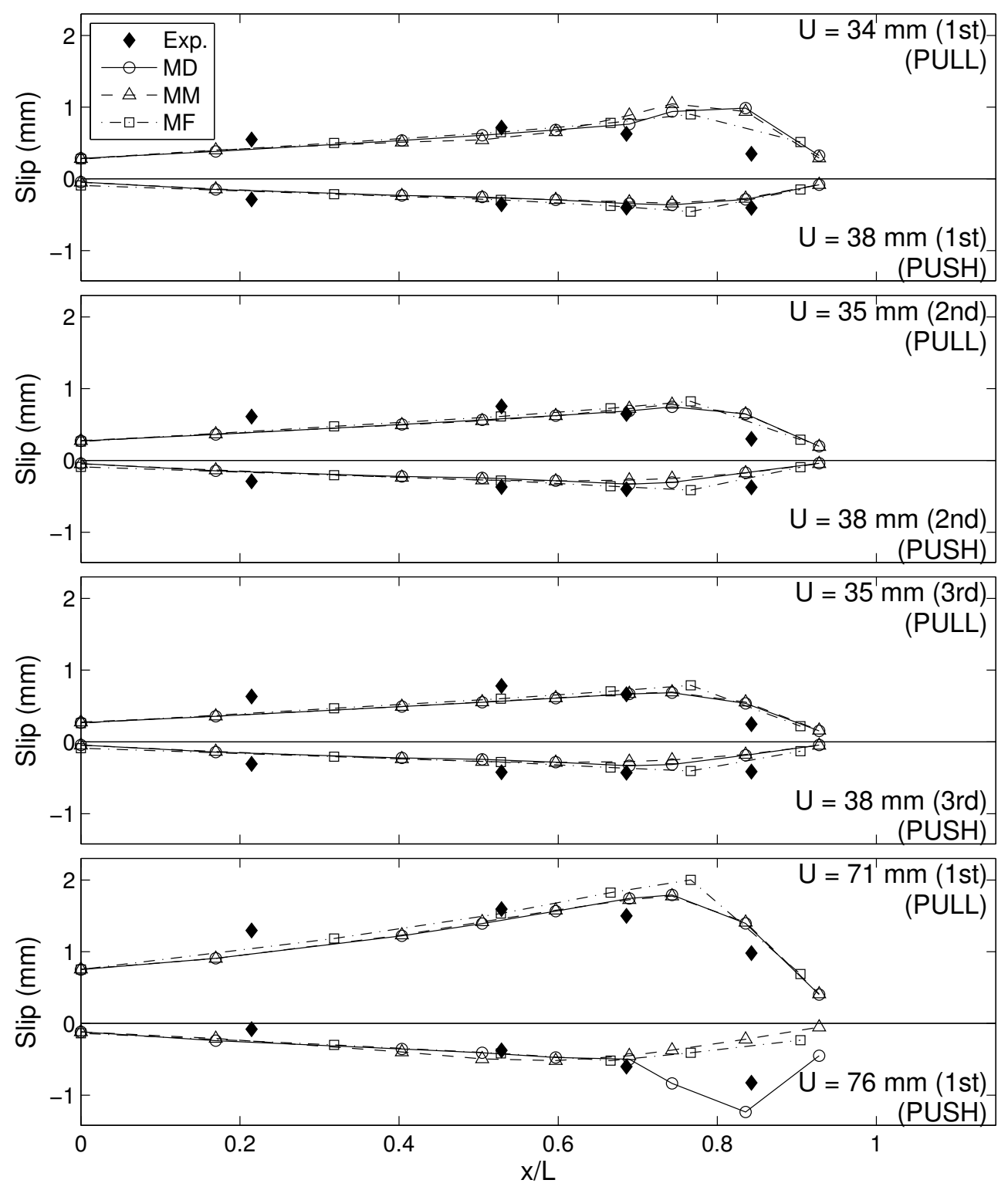

FIG. 5. Comparison of the slip distribution at a peak displacement of $35 \mathrm{~mm}$ for three loading cycles and at a peak displacement of $75 \mathrm{~mm}$ for one cycle 


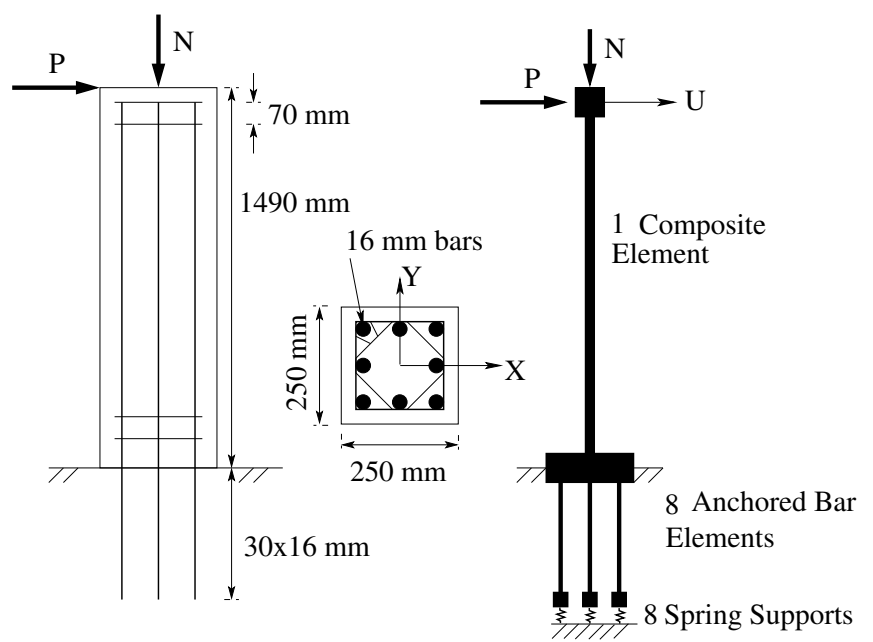

(a) Numerical model

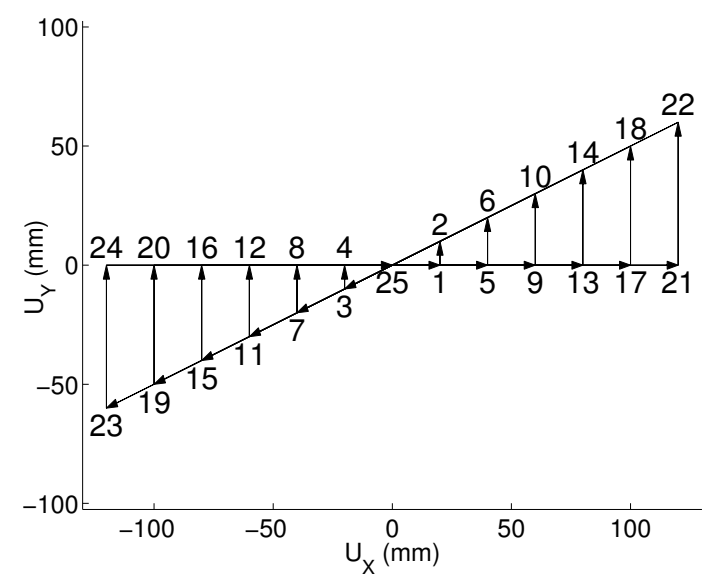

(b) Lateral displacement history

FIG. 6. Specimen geometry, numerical model, and displacement load history for square RC column specimen by Bousias et al. (1995) 

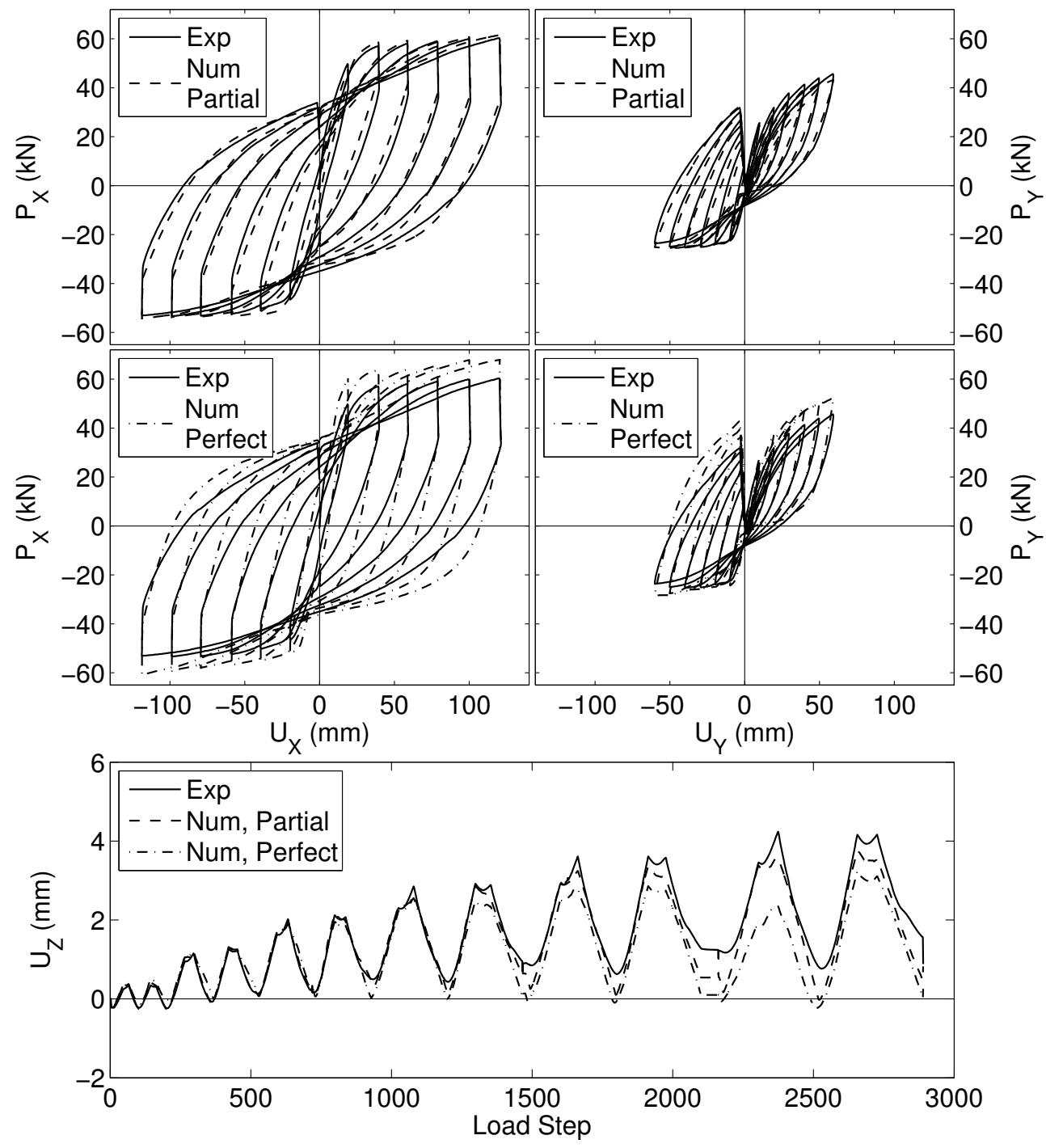

FIG. 7. Force-displacement relation and axial displacement history for the RC cantilever column specimen by Bousias et al. (1995) 


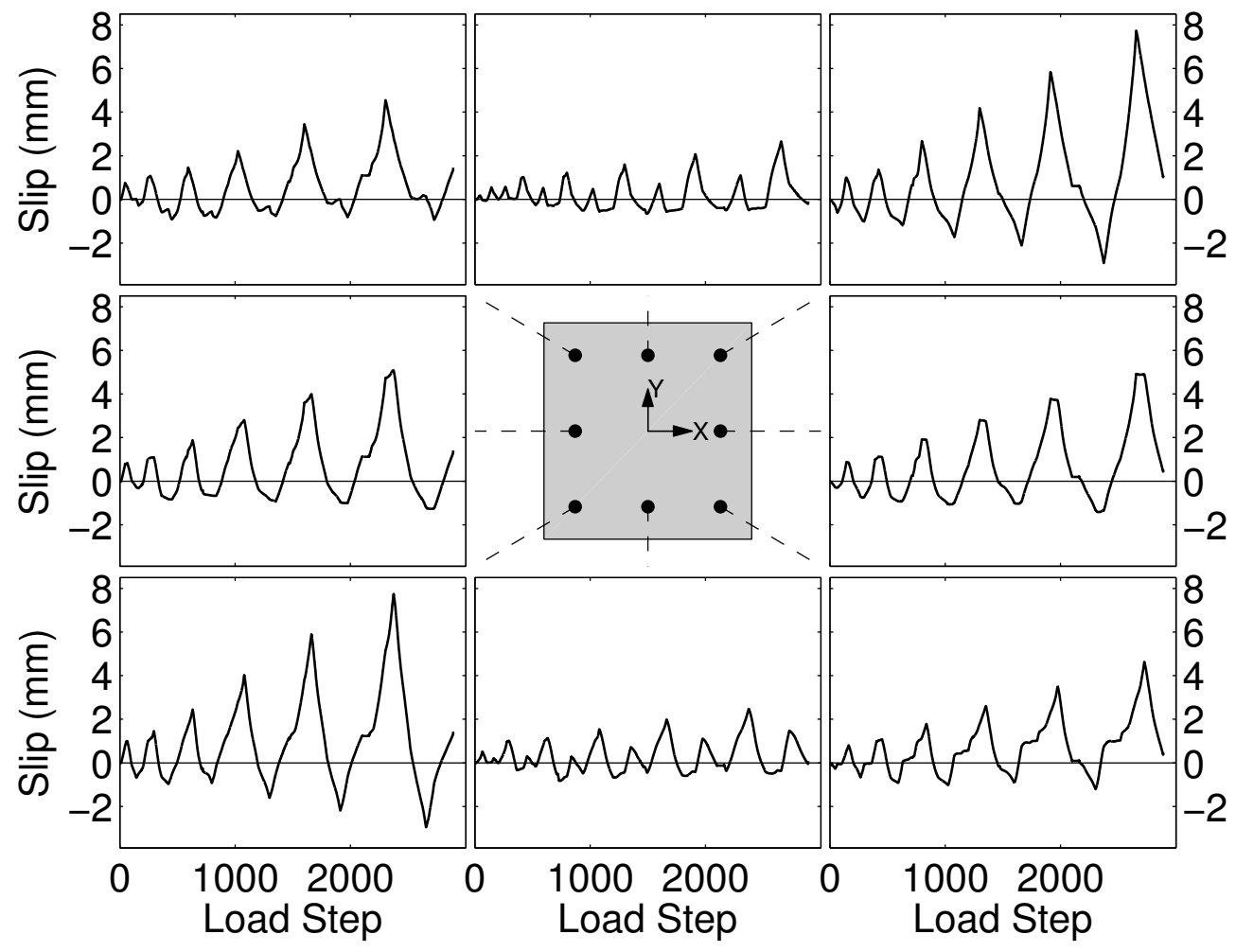

FIG. 8. Reinforcing bar slip history at the base of the RC cantilever column by Bousias et al. (1995) 


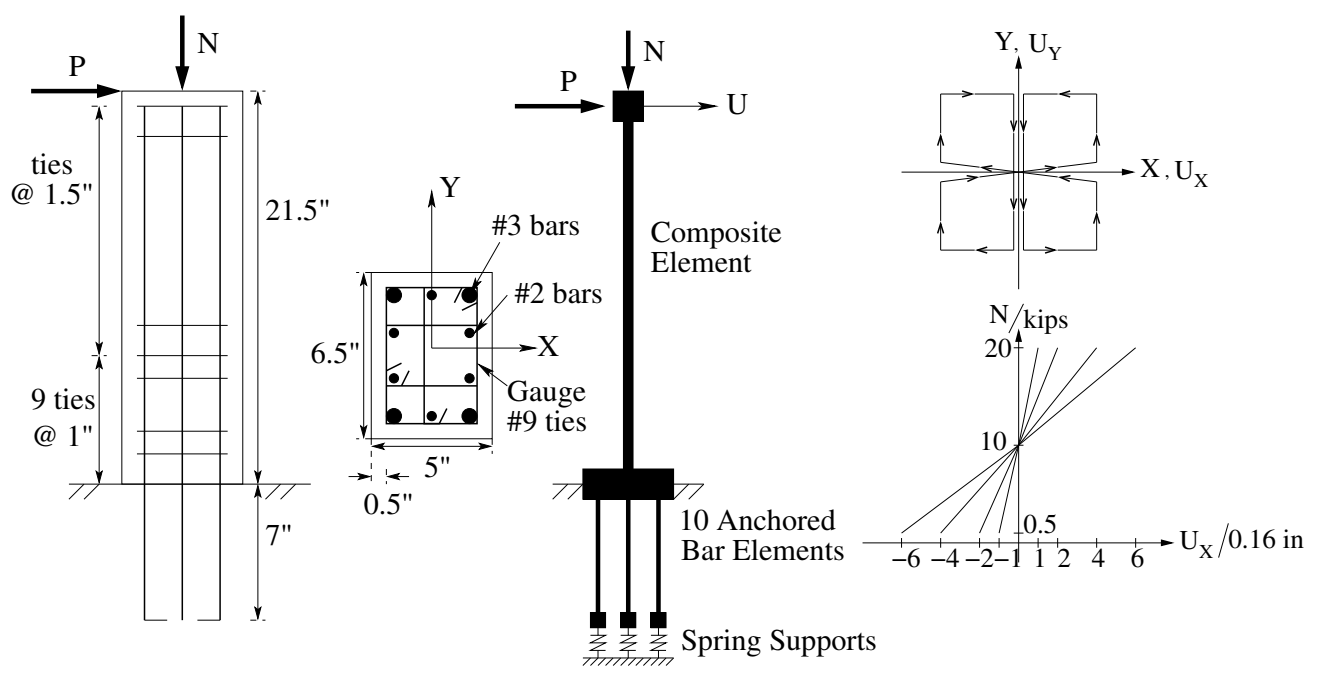

FIG. 9. Specimen geometry, numerical model, and force and displacement load history for rectangular RC column specimen by Low and Moehle (1987) 

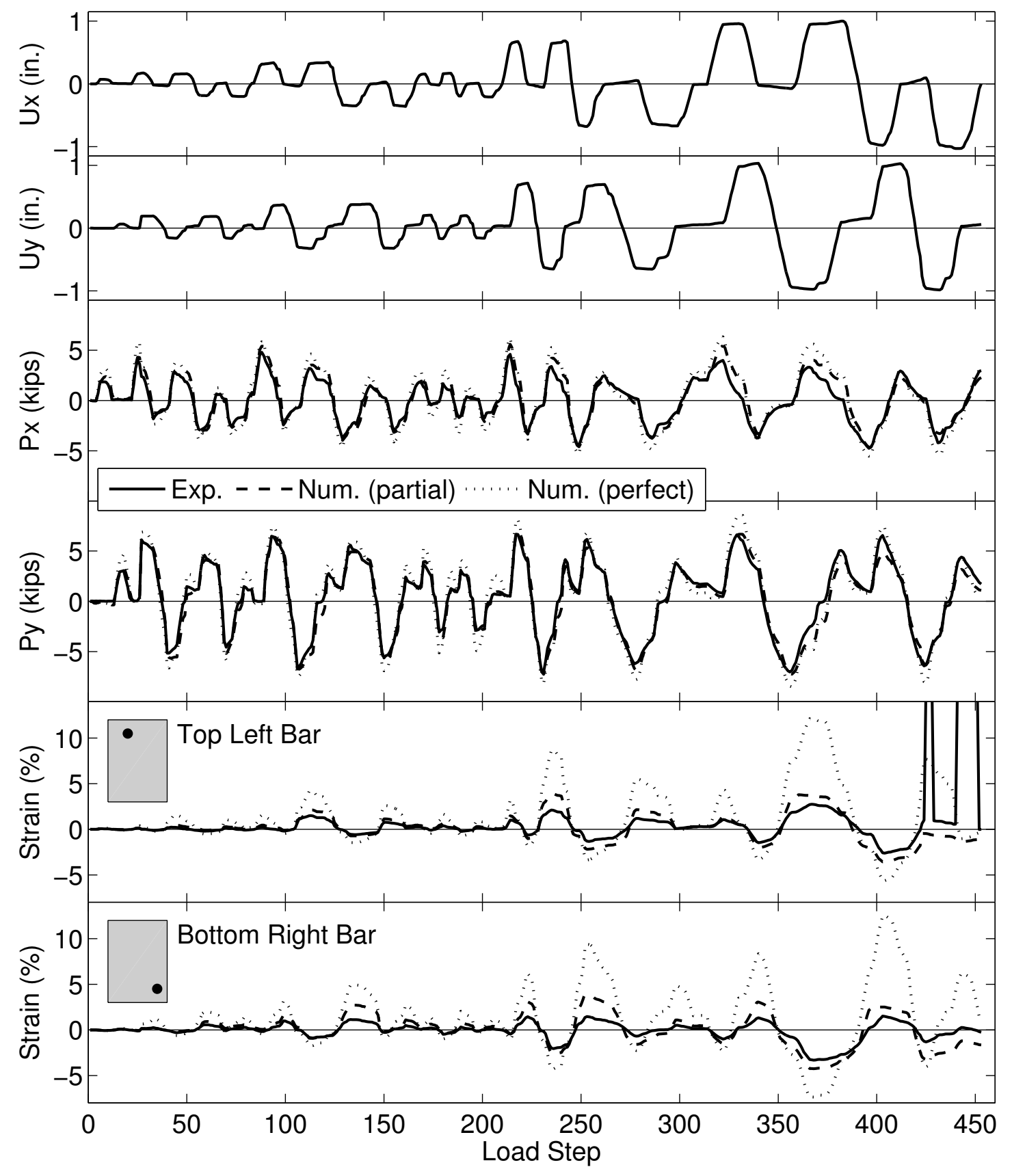

FIG. 10. Comparison of numerical results for the RC cantilever column strength history and the reinforcing bar strain histories with experimental measurements by Low and Moehle (1987) 